\title{
STUDI FENOMENOLOGI : DUKUNGAN TERHADAP KEPATUHAN MINUM OBAT PADA PENDERITA TUBERCULOSIS DENGAN MULTIDRUG-RESISTANT
}

\author{
Murwanti $^{1)}$, Kusbaryanto ${ }^{2)}$ \\ Universitas Muhammadiyah Yogyakarta \\ e-mail : murwanti1010@gmail.com
}

\begin{abstract}
Background: Tuberculosis is an infectious disease if the patient does not complete therapeutic treatment can cause multidrug-resistant tuberculosis (MDR-TB). The role of the environment is needed to support treatment.The study aims to explore more deeply the family's support for medication adherence in patients with multidrug-resistant tuberculosis (TBC-MDR). Method: This type of research is qualitative using a descriptive phenomenological approach, in-depth interviews of 5 participants based on purposive sampling technique. Results: The results of the study found the role of the family towards TB-MDR patients manifested in emotional, physical, instrumental, and spiritual support. emotional support consists of positive and negative emotional. Community involvement after counseling was supportive but there were some who could not accept even families of MDR-TB sufferers were also shunned. The role of health services is to convey information, prepare medicines, supervise, motivate treatment, remind check schedules, refer to more complete facilities when needed, visit homes and ensure patients take medication if unable to come to the public health service. Conclusion: This study found 3 main themes, namely the role of comprehensive family, community involvement and the role of health services in mentoring TBMDR patients.
\end{abstract}

Keywords: Phenomenology, Support, Compliance with Medication, TB-MDR

\section{PENDAHULUAN}

TBC merupakan penyakit yang dapat ditularkan melalui udara. TBC merupakan salah satu dari 10 penyebab kematian di seluruh dunia, penyebab utama kematian berkaitan dengan resistensi antimikroba (WHO, 2017). Penanganan TBC memerlukan upaya pencegahan dan pengendalian yang terkoordinasi antara pihak internasional dan nasional (PCP-HN, 2013). Penderita yang tidak menyelesaikan terapi pengobatan dapat menyebabkan Multidrug-resistant TBC (MDR-TB). MDR-TBC disebabkan oleh organisme yang tahan terhadap setidaknya isoniazid dan rifampisin.

Tahun 2016, ada 10,4 juta kejadian TBC di seluruh dunia, diantaranya adalah 6,2 juta laki-laki, 3,2 juta perempuan dan 1 juta anakanak. Tujuh negara menyumbang $64 \%$ dari kasus baru : India, Indonesia, China, Filipina, Pakistan, Nigeria, dan Afrika Selatan. TBC menyebabkan 1,7 juta orang meninggal. WHO memperkirakan bahwa ada 600.000 kasus baru dengan resistensi terhadap rifampisin, termasuk 490000 dengan TBCMDR, 6,2\% orang dengan TBC-MDR.
Indonesia menempati urutan ke 8 dari 27 negara dengan TBC-MDR terbanyak (WHO, 2017).

Pada tahun 2017 yang merupakan data per 2017 sampai dengan Mei 2018 menyebutkan angka kejadian TBC di Indonesia mencapai 420.994 kasus, dengan TBC-MDR sebanyak 32.000 kasus (Kemenkes RI, 2018). Di Propinsi Daerah Istimewa Yogyakarta (DIY) pada tahun 2017 terdapat 992 penderita TBC dengan pasien TBC-MDR sejumlah 66 orang.

Data dari dinas kesehatan Kabupaten Bantul pada tahun 2017 terdapat 280 penderita TBC, dengan data per Juni 2017 sampai dengan Agustus 2018 penderita TBCMDR sejumlah 8 penderita. Berdasarkan data angka kesembuhan TB DIY pada tahun 2017, Kulon Progo mencapai 80\%, Bantul 65\%, Gunung Kidul 83,87\%, Sleman 91,64\%, Kota Yogyakarta 77,64\% dan DIY 85,56\% (Profil Kesehatan Kab/ Kota, 2017).

Penyebaran TBC terjadi karena Basil mycobacterium tuberculosis yang ditularkan melalui aerosol, terutama akibat dari batuk. Penularan dapat terjadi ketika kontak dengan 
seseorang yang memiliki riwayat TBC sehingga dapat berisiko menularkan infeksi (Raviglione, 2014). Infeksi bakteri TBC dapat terjadi karena menghirup droplet yang mengandung bakteri TBC bersumber dari dahak penderita melalui batuk, bersin, tertawa, menyanyi atau memainkan instrumen musik dengan cara ditiup (Yukon, 2016). Faktor lain yang perlu diperhatikan adalah resistensi terhadap beberapa obat yang digunakan untuk mengobati TBC (PCP-HN, 2013). Berbagai cara penularan infeksi TBC berupa wadah minum atau peralatan makan, berbagi rokok dengan orang lain serta air liur dari hasil ciuman bersama dengan penderita TBC (CDC, 2015).

Pengalaman dan pemahaman tentang masalah kesehatan menjadi faktor utama bagi ketahanan diri mereka. Ketika tingkat pemahaman kesehatan rendah penderita lebih rentan terhadap ketidakpatuhan terhadap rejimen terapi (Wilson et al., 2016). Ketidakpatuhan mengakibatkan resistensi terhadap obat serta mempersulit program pengobatan yang dapat meningkatkan mortalitas dan morbiditas. Meskipun telah ada vaksin sejak tahun 1930-an, memberikan perlindungan anak usia dini terhadap penularan TBC, tidak menutup kemungkinan seseorang akan tertular infeksi TBC (Raviglione, 2014).

Kepatuhan menjalankan terapi memainkan peran penting dalam keberhasilan sebuah terapi. Ketidakpatuhan penderita yang mengkonsumsi obat TBC merupakan penyebab paling penting dari kegagalan terapi dan mengakibatkan kekambuhan kembali. Ketidakpatuhan dapat mengakibatkan kerentanan bagi penderita TB (Sinha, 2010). Dukungan dari lingkungan sangat diperlukan dalam sebuah keberhasilan terapi. Dukungan dapat berupa dukungan emosional, dukungan instrumental, dukungan informasi dan dukungan penilaian.

Berdasarkan fenomena diatas penulis tertarik membahas tentang "Studi fenomenologi : dukungan terhadap kepatuhan minum obat pada penderita tuberculosis Multidrug-resistant (TBC-MDR) di Kabupaten Bantul".
Desain penelitian kualitatif dengan pendekatan studi fenomenologi digunakan untuk menyelesaikan masalah penelitian. Tujuan dasar dari studi fenomenologi adalah menguraikan pengalaman individu terhadap suatu fenomena dengan mendeskripsikan secara keseluruhan

Partisipan dalam penelitian ini adalah keluarga penderita TB-MDR yang berdomisili di Kabupaten Bantul. Penentuan partisipan menggunakan tipe purposive sampling. Partisipan dalam penelitian ini berjumlah 5 orang. Alat pengumpulan data penelitian menggunakan pedoman wawancara, voice reorder dan field notes, dengan jenis analisa menggunakan analisa tematik menggunakan metode coalizi.

\section{HASIL PENELITIAN}

Dukungan keluarga memiliki peranan penting dalam keberhasilan atau kepatuhan penderita TBC dalam minum obat. Hasil analisis tematik dari penelitian ini ditemukan 3 tema utama yaitu 1) peran keluarga yang komprehensif terhadap pendampingan pasien TBC-MDR, 2) keterlibatan masyarakat terhadap pasien TBC-MDR, dan 3) peran pelayanan kesehatan dalam pendampingan pasien TBC-MDR.

\section{METODE PENELITIAN}


Tema ini terbentuk dari beberapa subtema, kategori, dan kode. Gambar berikut ini menjelaskan alur kategori hingga sub tema membentuk sebuah tema hasil penelitian ini :
Kategori
Sub Tema
Tema

\begin{tabular}{|l|}
\hline Emosional positif \\
\hline Emosional negatif \\
\hline Kebutuhan makan \\
\hline
\end{tabular}

\begin{tabular}{l|}
\hline $\begin{array}{l}\text { Dukungan } \\
\text { emosional }\end{array}$ \\
\hline
\end{tabular}

\begin{tabular}{|l|}
\hline Mobilisasi \\
\hline Pemeriksaan kesehatan \\
\hline Toileting \\
\hline
\end{tabular}

Dukungan fisik

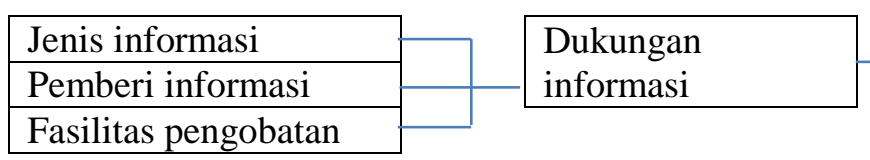

\begin{tabular}{|l|l|}
\hline $\begin{array}{l}\text { Penanggung jawab } \\
\text { biaya }\end{array}$ & \\
\hline Pendamping kontrol & \\
\hline Transportasi & \\
\hline
\end{tabular}

Dukungan instrumental

\begin{tabular}{|l|l|}
\hline Berdoa \\
\hline Mengenal masalah \\
\hline Mengambil keputusan \\
\hline $\begin{array}{l}\text { Mengenal masalah } \\
\text { TBC-MDR }\end{array}$ \\
\hline $\begin{array}{l}\text { Merawat keluarga } \\
\text { yang sakit }\end{array}$ \\
\hline Menjaga lingkungan \\
\hline
\end{tabular}

Peran Keluarga yang Komprehensif

Terhadap

Pendampingan Pasien

TBC-MDR

Skema 1 Tema 1 Peran Keluarga yang Komprehensif Terhadap Pendampingan Pasien TBC-MDR

Kategori

Sub Tema

Tema

\begin{tabular}{|c|c|c|}
\hline $\begin{array}{l}\text { Tetangga berespon } \\
\text { positif }\end{array}$ & Sikap tetangga & Keterlibatan \\
\hline $\begin{array}{l}\text { Tetangga berespon } \\
\text { negatif }\end{array}$ & & $\begin{array}{l}\text { masyarakat terhadap } \\
\text { pasien TBC-MDR }\end{array}$ \\
\hline
\end{tabular}

Skema 2 Tema 2 Keterlibatan masyarakat terhadap pasien TBC-MDR 
Kategori

Sub Tema

Tema

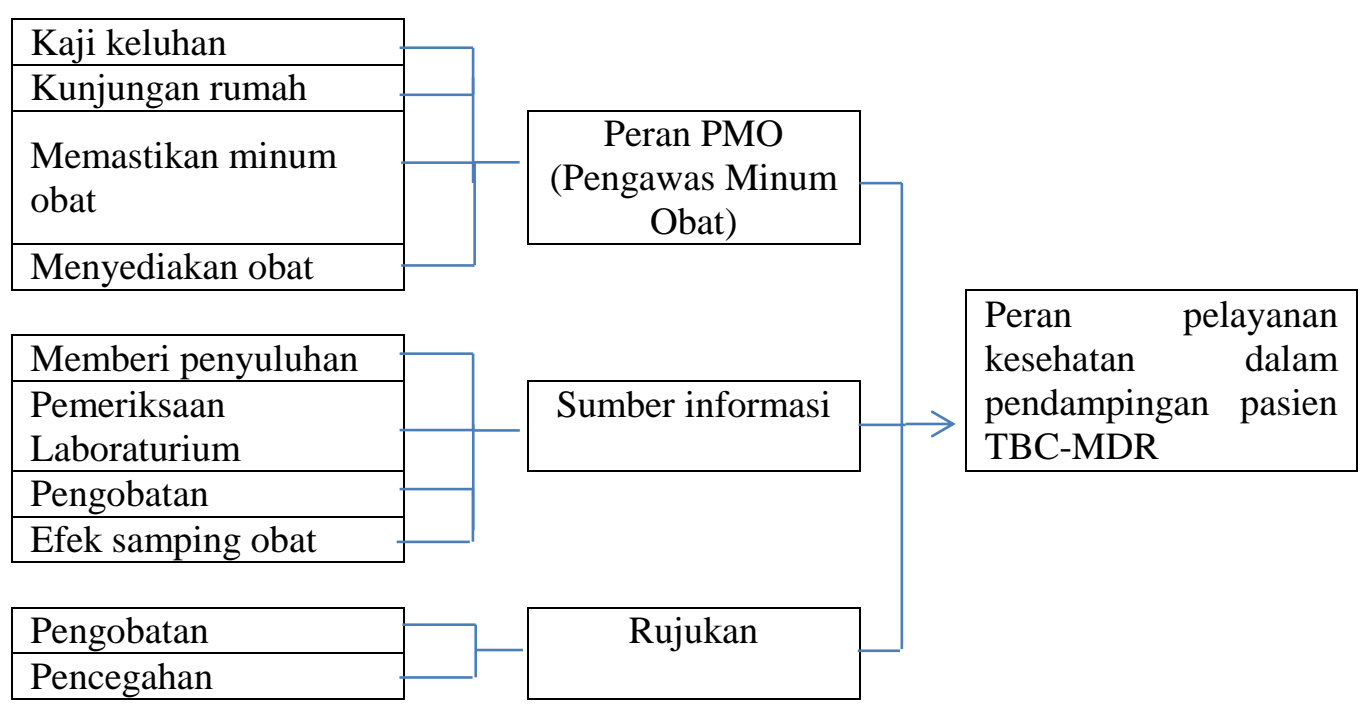

Tabel 3 Tema 3 Peran pelayanan kesehatan dalam pendampingan pasien TBC-MDR

Tema 1 ditemukan berupa peran keluarga yang komprehensif terhadap pendampingan pasien TBC-MDR, tema ini dibentuk dari dukungan antara lain dukungan emosional, dukungan fisik, dukungan informasi, dukungan instrumental, dukungan spiritual dan tugas keluarga.

Berikut ini pernyataan yang mendukung terbentuknya tema 1 :

Dukungan emosional positif

"...Kami sekeluarga ngasih motivasi, yakin sembuh setelah rutin berobat...”(P4)

“...Saya mendengarkan dan bilang pelanpelan Pak diacuhkan saja rasa mual, muntah pusing sama rasa pahit saat makan...'(P1)

Dukungan emosional negative

“...ya kadang merasa terbebani karena saya kan kerja ikut orang sementara setiap hari harus standby kalau ada apa-apa..."(P4)

“...saya sebenarnya yang sempat down saat tahu suami saya kena TBC-MDR...”(P2)

Pernyataan yang mendukung tema 2 sebagai berikut :

Respon tentangg positif

"Di lingkungan sini saya juga ngasih tahu ke Pak RT dan tetangga kalau Bapak baru sakit yang membuat Bapak tidak bisa ikut
kegiatan.....(P2)

Respon tetangga negative

“.....Eeemmm......(Ibu P. terdiam) sambil berkaca-kaca mengatakan kalau tetangga kayaknya pada menjauh Mbak, mungkin mereka tahu Bapak sakit MDR. Soalnya khan setelah Bapak pengobatan ini dari Puskesmas mengadakan penyuluhan gitu....'(P4)

Pernyataan yang mendukung tema 3 sebagai berikut :

Menyediakan obat

"Kalau hari-hari kan ke Puskesmas untuk minum obat itu.”(P1)

Pemeriksaan laboratorium

“....di Rumah sakit Panembahan Senopati Bantul bakterinya banyak dan dicek juga oleh dokter patologi...”(P3)

\section{PEMBAHASAN}

Berdasarkan analisa tematik pada penelitian ini ditemukan 3 (tiga) tema utama yaitu peran keluarga yang komprehensif terhadap pendampingan pasien TBC-MDR, keterlibatan masyarakat terhadap pasien TBC-MDR dan Peran pelayanan kesehatan. Berikut analisa dari masing-masing tema :

Peran Keluarga yang Komprehensif 


\section{terhadap Pendampingan Pasien TBC- MDR}

Peran keluarga dianggap sebagai salah satu variabel penting yang mempengaruhi hasil perawatan pasien TBC-MDR. Pemberi perawatan dalam keluarga memberikan dukungan emosional, dukungan fisik, dukungan informasi, dukungan instrumental, dukungan spiritual terhadap penderita TBCMDR (Friedman, 2013; FSP ${ }^{\mathrm{TM}}$, 2015).

Berdasarkan hasil penelitian disimpulkan bahwa peran keluarga terhadap pasien TBC-MDR terwujud dalam dukungan emosional, dukungan fisik, dukungan instrumental, dan dukungan spiritual.

Dukungan emosional terdiri dari emosional positif dan negatif. Emosional positif meliputi memberi pujian, mendengarkan saat diajak diskusi, memotivasi, pendampingan, penerimaan, pikiran positif, dan simpati. Selain rasa kepedulian sebagai bentuk dukungan emosional yang positif, ada juga emosional negatif seperti perasaan negatif merasa terbeban dan penolakan (dijauhi) orang lain. Pasien TBC-MDR sudah merasa berat dalam menjalani pengobatan akan semakin berat tanpa ada dukungan dari keluarga. Sementara partisipan sendiri yang merupakan keluarga dari penderita TBC-MDR ternyata mempunyai beban tersendiri yaitu rasa takut dijauhi orang lain.

Berdasarkan hasil penelitian (Gooty, Shumski, Yammarino, Kim, \& Medaugh, 2019) bahwa emosional positif dan negatif dalam suatu hubungan adalah heuristik yang memandu timbal balik terhadap hubungan lain. Bentuk dukungan yang diberikan adalah kebutuhan makan, mobilisasi pemeriksaan kesehatan, dan toileting. Berdasarkan House (1981) dalam Kaakinen (2010) mengemukakan bahwa dukungan fisik sebagai bentuk penghargaan yang memberikan umpan balik kepada individu untuk membantu mengevaluasi diri, dan menilai situasi.

Pasien TBC-MDR dengan semua keluhan dan kondisi penurunan imunitas, akan merasa tidak berdaya sehingga secara psikologis apabila tidak ada dukungan dari keluarga, berpengaruh pada kondisi emosional yang akhirnya mempengaruhi semangat menyelesaikan pengobatan. TBC memiliki dampak negatif yang luar biasa pada kualitas hidup pasien khususnya domain fisik yang paling terpengaruh (Sartika, Insani, \& Abdulah, 2019). Berdasarkan temuan penelitian yang dilakukan oleh (Sartika, Insani, \& Abdulah, 2019) bahwa meskipun ada penyembuhan mikrobiologis, $47 \%$ pasien terus mengalami gejala pernapasan.

Dukungan informasi dalam penelitian ini terdiri dari jenis informasi dan pemberi informasi. Jenis informasi yang diberikan mencakup diagnosa, penyebab, pengobatan, dan efek samping. Pemberi informasi terdiri dari keluarga, media dan tenaga kesehatan. Adanya informasi yang benar menjadi sarana keluarga dalam memberi perawatan di rumah pada penderita TBC-MDR agar mampu menyelesaikan terapi pengobatannya. Peningkatan peran keluarga dan bertambahnya pengetahuan di pihak keluarga akan memberikan manfaat yang positif bagi klien dalam menjalani proses pengobatan. Hal ini sejalan dengan penelitian (Mar, Nursasi, \& Wiarsih, 2019) bahwa dukungan informasi penting untuk pengobatan dan pemberdayaan keluarga dalam memberikan dukungan informasi untuk meningkatkan efikasi diri di antara klien tuberculosis. Hasil penelitian juga bahwa klien TBC dengan dukungan keluarga lebih sedikit berisiko 4.047 kali efikasi diri rendah dibandingkan dengan klien dengan dukungan keluarga yang lebih baik (Jauhar, Nursasi, \& Wiarsih, 2019).

Dukungan instrumental dalam penelitian ini tercakup dalam fasilitasi pengobatan, penanggung jawab biaya, pendamping kontrol, dan transportasi. Berdasarkan House (1981) dalam Kaakinen (2010) mengemukakan bahwa dukungan instrumental memberikan bentuk nyata, seperti finansial, benda, atau pelayanan. Berdasarkan penelitian yang dilakukan oleh (Merluzzi, Philip, Yang, \& Heitzmann, 2016) bahwa orang yang membutuhkan dukungan seperti debilitasi fisik yang lebih besar namun tidak menerimanya akan mengalami lebih banyak kesusahan daripada orang yang membutuhkan dan menerima dukungan. Temuan lain dalam penelitian ini adalah adanya dukungan spiritual melalui berdoa dan berusaha. Adanya dorongan dari 
keluarga kepada penderita TBC-MDR menjalani pengobatan dan bersama-sama keluarga memanjatkan doa, serta menyerahkan semuanya kepada Tuhan bukan sebagai kepasrahan, tetapi sebagai bentuk keyakinan bahwa Tuhan yang menyembuhkan sedangkan obat adalah sarana dalam kesembuhan. Keluarga dijadikan sebagai salah satu sumber dukungan yang dapat memberikan rasa percaya kepada sang pencipta untuk mengatasi segala masalah yang dihadapi seseorang serta kepercayaan atas doa yang di panjatkan (Friedman, 2013).

Berdasarkan hasil penelitian (Sadipun, Dwidiyanti, \& Andriany, 2018) bahwa intervensi mindfulness berbasis spiritual memiliki efek yang signifikan untuk meningkatkan kontrol emosional pasien dewasa dengan TB paru dan sebagai salah satu upaya untuk mengendalikan emosi pasien TB paru serta mempercepat proses penyembuhan.

Lebih lanjut berdasarkan penelitian (Szaflarski, 2013) bahwa spiritualitas dan agama penting yang dapat meningkatkan kesehatan atau kualitas hidup secara langsung dan melalui faktor mediasi (perilaku sehat, optimisme, dukungan sosial)

\section{Keterlibatan Masyarakat terhadap Pasien TBC-MDR}

Temuan penelitian ini menyimpulkan bahwa keterlibatan masyarakat terhadap pasien TBC-MDR sebagai bentuk dari pemberi dukungan baik dari keluarga besar, keluarga inti, dan tetangga. Masyarakat terlibat dalam memberi dukungan setelah mendapatkan informasi melalui penyuluhan dari tenaga kesehatan tentang TBC-MDR saat ada anggotanya yang menderita TBCMDR. Penyuluhan ini sangat mendukung untuk menyampaikan informasi yang benar tentang TBC-MDR di keluarga dan masyarakat, sehingga masyarakat bisa dengan bijkasana memperlakukan penderita TBC-MDR dan keluarganya tanpa menjadikan terkucil.

Berdasarkan penelitian ini masyarakat memberi perhatian baik berupa perhatian/dukungan positif maupun negatif sebagai bentuk dukungan kepada penderita TBC-MDR, hal ini berpengaruh pada peningkatan kepercayaan diri penderita TBCMDR bahwa dirinya di terima di masyarakat tanpa mengabaikan sebagian masyarakat yang menjauhi.

Dari penelitian ini keluarga juga menyadari meskipun sudah diberikan informasi yang benar tentang TBC-MDR dari tenaga kesehatan, masyarakat ada yang menerima dan mendukung tetapi ada sebagian masyarakat yang belum bisa menerima pasien TBC-MDR bahkan keluarga penderita TBC-MDR ikut dijauhi. Hal ini menjadi penyemangat dan merekatkan keluarga untuk bersatu, memperhatikan dan peduli kepada penderita, dengan mengabaikan perlakuan sebagian masyarakat sekitar yang belum bisa menerima, mereka menyadari hanya keluarga yang menjadi harapan untuk memotivasi dan mendukung sepenuhnya, yang pada akhirnya akan menjadi penyemangat bagi pasien untuk menyelesaikan terapi pengobatan.Anggota keluarga sangat efektif dan efisien dalam mendukung penyembuhan penderita TBC karena tidak mengedepankan reward berupa materi sebagai imbalan jasa tetapi dimotivasi oleh kedekatan keluarga yang disadari oleh pengabdian yang tulus, iklas, sabar, cinta, kasih sayang dan tanggung jawab sebagai implementasi nilai keyakinan (Syahrial, 2013).

Upaya yang dilakukan fokus pada kelompok yang rentan; menangani intervensi khusus populasi di tingkat individu dan masyarakat. Implikasi klinis dan kebijakan lintas pengaturan geografis juga perlu diperhatikan (Szaflarski, 2013).

\section{Peran Pelayanan Kesehatan terhadap Pasien TBC-MDR}

Peran pelayanan kesehatan terhadap pasien TBC-MDR antara lain peran pengawas minum obat (PMO). Peran dan tugas seorang PMO adalah mengawasi pasien TB agar menelan obat secara teratur sampai selesai pengobatan, memotivasi pasien agar mau berobat teratur. Mengingatkan pasien untuk periksa ulang dahak pada waktu yang telah ditentukan, PMO melakukan rujukan ke rumah sakit sesuai rekomendasi dokter penanggung jawab apabila penderita TBCMDR perlu mendapat pelayanan rujukan. Memberi penyuluhan pada anggota keluarga 
pasien TB yang mempunyai gejala-gejala mencurigakan TB untuk segera memeriksakan diri ke Unit Pelayanan Kesehatan.

Tugas seorang PMO bukanlah untuk mengganti kewajiban pasien mengambil obat dari unit pelayanan, tetapi dalam kondisi tertentu seorang PMO atas kesadarannya memperhatikan pasien TBC-MDR, dengan memberikan pelayanan saat pasien tidak bisa ke puskesmas untuk minum obat, PMO mendatangi rumah pasien untuk memastikan bahwa pasien tetap mendapat pelaayanan minum obat di hari itu. Pentingnya pengawasan supaya pasien berobat teratur. Kemungkinan terjadinya efek samping obat dan perlunya segera meminta pertolongan ke Unit Pelayanan Kesehatan (UPK) (Putri, 2019).

Berdasarkan penelitian Sukoco (2013) menyatakan bahwa keberadaan PMO mempunyai hubungan yang signifikan dengan hasil akhir pengobatan. Pelayanan kesehatan juga berperan sebagai sumber informasi terkait TBC-MDR ke masyarakat secara umum. Hal ini untuk meluruskan informasi TBC khususnya TBC-MDR tentang apa itu pengertian TBC-MDR, penularannya, bagaimana pengobatan serta efek sampingnya, bagimana cara menghindari, keikutsertaan masyarakat berperan memberi dukungan bagi penderita dalam pengobatan serta meminimalisir penyebaran penyakit TBC-MDR. Hasil penelitian ini menemukan bahwa tenaga kesehatan sudah melakukan antsipasi penularan dan mencegah terjadinya penularan, cara yang dilakukan yaitu dengan penyuluhan di masyarakat, terutama masyarakat sekitar penderita TBC-MDR agar memudahkan masyarakat memahami dan mendapat informasi yang benar, akurat, tepat dan lengkap. Setelah ada penyuluhan dari tenaga kesehatan, masyarakat ada yang bisa menerima sehingga tetap bergaul dengan penderita TBC-MDR, ada juga yang belum menerima dengan menjauhi pasien bahkan keluarganya. Petugas kesehatan juga mengambil dahak keluarga dan teman dari pasien untuk dilakukan pemeriksaan spesimen dahak. Tujuan dari pengambilan spesimen, salah satunya untuk mengetahui secara dini apabila ada penularan dan secepatnya dilakukan pengobatan.

Berdasarkan penelitian Wilson J.W., Ramos J.G. (2016) menyatakan bahwa setelah melihat video edukasi $\mathrm{TBC}$, kesan pasien menunjukkan pemahaman TB yang lebih besar termasuk bagaimana cara menularkan dan keberhasilan pengobatan, dan juga, pandangan diagnosis yang lebih optimis. Anggota keluarga yang melihat video tersebut menunjukkan rasa takut dan minat mengetahui tentang TBC yang lebih besar dan juga menunjukkan dukungan lebih untuk keluarga yang menjalani perawatan sampai evaluasi.

Peran pelayanan kesehatan yang lain adalah sebagai sumber rujukan. Pelayanan kesehatan menjadi salah satu rujukan baik secara laboraturium untuk memastikan seseorang terdiagnosa TBC-MDR, juga rujukan terapi pengobatan. Adanya sistem pelayanan kesehatan yang sistematis dan gratis bagi penderita TBC-MDR, sangat memudahkan dan membantu seorang penderita TBC-MDR mendapatkan penanganan dan pengobatan. Lamanya waktu pengobatan dan jadwal rutin minum obat menjadikan efek samping dari pengobatan kadang tidak bisa dihindari. Efek samping obat ini sering menjadi keluhan penderita TBC-MDR sehingga apabila tidak ditangani secara benar akan mengakibatkan penderita TBC-MDR berhenti menjalani pengobatan. Dari penelitian ini disimpulkan bahwa peran tenaga kesehatan sangat membantu pasien TBC-MDR mendapatkan penangan lanjut lebih cepat terhadap keluhan efek samping obat. Tenaga kesehatan akan mendatangi rumah pasien, untuk memberi dan memastikan obat tetap diminum apabila kondisi pasien tidak memungkinkan datang rutin minum obat ke puskesmas. Tenaga kesehatan juga melakukan rujukan atas rekomendasi dokter puskesmas, apabila kondisi pasien tidak memungkinkan dirawat dipuskesmas dan memerlukan penanganan akibat efek samping obat, serta pemeriksaan lainnya ke fasilitas kesehatan yang lebih lengkap untuk mengetahui perkembangan dari pengobatan.

Berdasarkan penelitian (Khachadourian V., Truzyan N., 2015) melakukan check up rutin pada pasien sesuai jadwal, memberi respon secara cepat pada keluhan efek 
samping pengobatan TBC, dan melaporkan ke dokter untuk tindak lanjut secara psikologis membantu mengurangi kekawatiran pasien dan keluarganya.

\section{SIMPULAN}

Tiga tema yang mendukung kepatuhan penderita TBS-MDR dalam pengobatan antara lain peran keluarga yang komprehensif terhadap pendampingan pasien TBC-MDR, keterlibatan masyarakat terhadap pasien TBC-MDR dan peran pelayanan kesehatan dalam pendampingan pasien TBC-MDR. Peran keluarga terhadap pasien TBC-MDR terwujud dalam dukungan emosional, dukungan fisik, dukungan instrumental, dan dukungan spiritual. Keterlibatan masyarakat terhadap pasien TBC-MDR sebagai bentuk pemberi dukungan. Adanya penyuluhan memberi informasi yang benar tentang TBCMDR di keluarga dan masyarakat, sehingga masyarakat dapat bijaksana memperlakukan penderita TBC-MDR. Peran pelayanan kesehatan terkait TBC-MDR sangat dibutuhkan sebagai upaya promotif, preventif dan rehabilitative.

\section{DAFTAR PUSTAKA}

Allyn, P.R., 2018. Guide to Infection Control in the Hospital; Chapter 23: Tuberculosis.

Arif, M, 2018. Hubungan Dukungan Keluarga dengan Kepatuhan Minum Obat pada Pasien Diabetes Melitus Tipe 2 di Ruang Poli Penyakit Dalam RSUD Dr. Achmad Mochtar Bukittinggi Tahun 2017. Prosiding Seminar Kesehatan Perintis, 1 (1): 110.

Beraldo, A.A., Andrade, R.L. de P., Orfão, N.H., Silva-Sobrinho, R.A. da, Pinto, É.S.G., Wysocki, A.D., Brunello, M.E.F., Monroe, A.A., Scatena, L.M., Villa, T.C.S., 2017. Adherence to tuberculosis treatment in Primary Health Care: perception of patients and professionals in a large municipality. Esc. Anna Nery 21. https://doi.org/10.1590/2177-9465ean-2017-0075

Biswas, B.R., 2010. The Relationship Between Family Support and Health Behaviors Among 109.
Castelnuovo B, 2010. A Review of Compliance to Anti Tuberculosis Treatment and Risk Factors for Defaulting Treatment in Sub Saharan Africa. Afr. Health Sci. 10, 320-324.

CDC, 2012. TB Elimination. MultidrugResistant Tuberculosis (MDR TB). Devision Tuberc. Elimin. 2.

Deshmukh D.J., D. e. (2017). Social Support a Key Factor Adherence to Multidrug-Resistant Tuberculosis Treatment. Indian Juornal Tuberculosis.

Fadlilah, N, 2016. Relationship Between Characteristics of Supervisory with Tuberculosis's Patient Compliance in Puskesmas Pragaan 2016. Jurnal Berkala Epidemiologi, 5 (3): 338-350.

Freadman, 1998. Keperawat Keluarga. Jakarta: EGC.

Freitas, I.M., Crispim, J. de A., Pinto, I.C., Villa, T.C.S., Brunello, M.E.F., 2012. Knowledge and Perception About Tuberculosis of Patients Familes Under Directly Observed Treatment at a Health Service in Ribeirao Preto-Sp Bazil. Text Context Nurs. Florianópolis 21, 644-649.

Hasanah, M., Makhfudli., Wahyudi, A.S, 2018. Hubungan DUkungan Keluarga dengan Efikasi Diri Penderita Tuberkulosis Multidrug Resistent (TBMDR) di Poli TB-MDR RSUD Ibnu SIna Gresik. Jurnal Kesehatan, 11 (2): 72-85.

Hendiani, N., Sakti, H., Widayanti, C.G, 2014. Hubungan antara Persepsi Dukungan Keluarga Sebagai Pengawas Minum Obat dan Efikasi Diri Penderita Tuberkulosis di BKPM Semarang. Jurnal Psikologi Undip, 13 (1): 82-91.

Irnawati, N.M, 2016. Pengaruh Dukungan Keluarga terhadap Kepatuhan Minum Obat pada Penderita Tuberkulosis di Puskesmas Motoboi Kecil Kota Kotamobagu. Jurnal Kedokteran Komunitas dan Tropik, 4 (1): 59-64.

Kaakinen, J.R., Duff, V.G., Coehlo, D.P., Hanson, S.M, 2010. Family Health Care Nursing. United States of America: F.A Davis Company. 
Kemenkes RI., 2015. Buku Saku Pasien TB MDR. Direktorat Jenderal Pengendaian Penyakit dan Penyehatan Lingkungan: Jakarta.

Kaulagekar-Nagarkar, A., Dhake, D., Jha, P., 2012. Perspective of Tuberculosis Patients on Family Support and Care in Rural Maharashtra. Indian J. Tuberc. 7.

Manuhara, L, 2012. Evaluasi Tingkat Kepatuhan Penggunaan Obat Tuberkulosis Paru pada Programmed Management on Drug-Resistant Tuberculosis di Puskesmas Kota Surakarta, Universitas Muhammadiyah Surakarta.

Mogan, R., Fajar, 2017. Relationship Between Family Support and Medical Compliance in Patients with Pulmonary Tuberculosis in the Working Area of the Community Health Center of Abeli, Kendari. Public Health of Indonesia, 3 (1): 1722.

Nesi, A., Subekti, I., Putri, R.M, 2017. Hubungan Dukungan dan Pengetahuan Keluarga dengan Tingkat Kepatuhan Berobat Penderita TBC Paru di Puskesmas Maubesi Kabupaten Timor Tengah Utara. Nursing News, 2 (2): 371-379.

Padilla-Díaz, M., 2015. Phenomenology in Educational Qualitative Research: Philosophy as Science or Philosophical Science? Int. J. Educ. Excell. 1, 101110.

https://doi.org/10.18562/IJEE.2015.00 09

Pan-Canadian Public Health Network, 2013. Guidance for tuberculosis prevention and control programs in Canada.

Pitters, T.S., Kandou, G.D., Nelwan, J.E, 2018. Dukungan Keluarga dala, Hubungannya dengan Kepatuhan Minum Obat pad a Pasien Tuberculosis Paru di Puskesmas Ranotana Weru. Jurnal Kesmas, 7 (5).
Profil Kesehatan Kab/ Kota, 2017. Profil Kesehatan Provinsi di Yogyakarta tahun 2017. Yogyakarta.

Raviglione, M.C., 2014. Tuberculosis Research in The Netherlands; Innovation to Accelerate Global Tuberculosis Elimination. KNCV Tuberculosis Foundation, Netherlends.

Ruminpunu, R., Maramis, F.R.R., Kolibu, F.K, 2018. Hubungan Antara Dukungan Keluarga dan Dorongan Petugas Kesehatan dengan Kepatuhan Berobat Penderita Tuberkulosis Paru di Puskesmas Likupang Kabupaten Minahasa Utara. Jurnal Kesmas, 7 (4).

Semiawan, C.R., 2010. Metode Penelitian Kualitatif; jenis, karakteristik dan keunggulannya. Grasindo, Jakarta.

Sinha, T., 2010. DOTS Compliance by Tuberculosis Patients in District Raipur (Chhattisgarh). Online J. Health Allied Sci. 9, 2.

Sitomorang, F.P., Kendek, R., Putra, W.F, 2017. Solusi Mengatasi Ketidakpatuhan Minum Obat Pasien Tuberkulosis.

https://www.researchgate.net/publicati on/319291820.

Truzyan, N., Crape, B., Harutyunyan, T., Petrosyan, V., 2018. Family-Based Tuberculosis Counseling Supports Directly Observed Therapy in Armenia: A Pilot Project. J. Tuberc. Res. 06, 113-124. https://doi.org/10.4236/jtr.2018.62011

Wilson, J.W., Ramos, J.G., Castillo, F., F. Castellanos, E., Escalante, P., 2016. Tuberculosis patient and family education through videography in El Salvador. J. Clin. Tuberc. Mycobact. Dis. 4, 14-20. https://doi.org/10.1016/j.jctube.2016.0 5.001

WHO, 2017. Multidrug-Resistant Tuberculosis (MDR-TB). World Health Organization.

Yukon, 2016. Basic Facts About Tuberculosis (TB). 